\title{
Features of non-malignant thoracic lesions on F-18 FDG PET/ CT scan
}

\author{
Ba D. Nguyen \\ Department of Radiology, Mayo Clinic, Scottsdale, United States. \\ Correspondence: Ba D. Nguyen. Address: Department of Radiology, Mayo Clinic, 13400 E. Shea Blvd, Scottsdale, AZ \\ 85259, United States. Email: nguyen.ba@mayo.edu
}

Received: September 18, 2014 Accepted: October 28, $2014 \quad$ Online Published: December 1, 2014

DOI : 10.5430/ijdi.v2n1p34 URL: http://dx.doi.org/10.5430/ijdi.v2n1p34

\begin{abstract}
Introduction: During PET/CT chest interpretation, the radiologist may encounter non-malignant positive findings originating from physiologic variants, inflammation, infection, iatrogenic causes, post-surgical/post-therapeutic changes and benign tumors of different components of the thorax. This article illustrates and raises the awareness of these benign FDG-avid findings.
\end{abstract}

Methods: We use a search engine to retrospectively review the 10-year PET/CT and pathology database of our institution for cases with thoracic findings linked to physiologic variations, and to benign processes and diseases. The keywords used for the search include all the entities presented in this article. We select the cases presenting with the most didactic value of benignity related to (1) established imaging patterns already published in the literature, which serves as reference articles in this paper, (2) final diagnosis from tissue sampling of ambiguous and difficult cases, and (3) long term monitoring based on clinical evaluation and anatomic and functional imaging.

Results: Among the pool of cases fulfilling the required search criteria, we choose the most illustrative ones to present the different categories of benign findings encompassing the physiologic variants, inflammation, infection, iatrogenic causes, post-operative and post-therapeutic changes, and benign neoplasms. The most representative reference articles of the presented cases concerning all the benign thoracic entities are selected for the bibliography.

Conclusion: The presented PET/CT cases raise the awareness and strengthen the interpretation confidence of the radiologist during the evaluation of cancer. The familiarity with these benign thoracic entities would obviate any suspicion of malignancy and avoid unnecessary additional assessment using expansive and potentially harmful procedures.

\section{Keywords}

Thorax, Benign findings, Positron emission tomography, Computed tomography

\section{Introduction}

Positron emission/ computed tomography (PET/ CT) imaging with [fluorine-18] fluoro-2-deoxy-D-glucose (FDG) is a combined functional and anatomic imaging modality widely used to evaluate, stage and monitor malignancy ${ }^{[1]}$. Abnormal areas of FDG accumulation are identified by qualitatively comparing the tracer uptake with normal background activity. However, FDG affinity is not malignancy-specific and during the PET/CT oncologic evaluation, radiologists may 
encounter incidental and/or co-existing FDG-avid findings, which are not related to the investigated malignant processes. This may lead to false-positive results and incorrect diagnostic predicaments, which may significantly impact the care and welfare of patients.

Accurate diagnosis can reduce unnecessary invasive procedures such as biopsy and thoracotomy in patients with benign disease ${ }^{[2]}$ and therefore familiarity with the different causes of increased F-18 FDG uptake in the thorax mimicking cancer is imperative. The pictorial essay encompasses inflammation, infection, physiologic variants, trauma, iatrogenic processes, post-therapeutic changes and benign diseases of the lung parenchyma, pleura, and different components of the mediastinum and chest walls. Each etiology is illustrated and discussed for optimized diagnosis based on its thoracic location.

\section{Objective}

Knowledge of the benign FDG-avid findings of the thorax will help the radiologist to provide an accurate PET/CT interpretation and to avoid false-positive diagnosis of malignancy.

\section{Methods}

The search engine Softek/Illuminate is used for inquiries of the F-18 FDG-avid benign thoracic entities in the 10-year PET/CT and pathology database of our institution. Keywords for the search encompass all the entities cited in the article from physiologic variations to benign neoplasms. All the selected cases are chosen for their established benignity, and for their excellent illustrative and teaching points. To support these presented cases and to enhanced their teaching abilities, PubMed and Google Scholar searches are performed using the similar keywords for the selection of pertinent papers describing, discussing and review the imaging features of benign thoracic diseases demonstrated by PET/CT.

\subsection{Physiologic variants}

Muscle tracer uptake is related to voluntary or involuntary exertion, increased insulin level or post-procedural changes. Positive uptake features are mostly demonstrated in the head and neck, trunk, extremities and diffusely throughout the body from different causes such as neck strain lying on stretcher, chewing gum, talking, finger tapping, cough, labored breathing, muscle spasms, jerking movement from seizure. Exertion up to 48 hours before PET/CT imaging may result in muscle uptake ${ }^{[3]}$. Familiarity with muscle uptake features (anatomic locations and symmetrical patterns) and knowledge of recent voluntary or involuntary exertion prior to PET/CT imaging are helpful to avoid false positive diagnosis of cancer (see Figure 1).

Brown adipose tissue is a well-known cause of false positive uptake on PET due to the hypermetabolic nature of the tissue ${ }^{[4,5]}$ Brown fat may be detected in $4 \%-5 \%$ of all PET/CT cases more frequently in women than in men ${ }^{[6]}$. The frequently encountered patterns of brown adipose tissue are bilateral and symmetrical at sites of CT-depicted fat tissue attenuation of sub-occipital, cervical, supraclavicular, axillary, paraspinal and intercostal regions (see Figure 2). Intermittently, brown fat deposit may be at less common and asymmetrical locations potentially leading to an interpretation error, specifically along the sternum mimicking internal mammary lymph nodes.

Myocardial metabolism may be from free fatty acid or glucose substrates depending on the fasting or non-fasting status. During oncologic imaging, the required patient's fasting forces the heart to use free fatty acid as substrate and should result in low and uniformed cardiac uptake features ${ }^{[7]}$. In real practice, the cardiac uptake patterns are variable even in serial PET exams of the same patient. F-18 FDG uptake by atrial appendages or atria is related to atrial fibrillation or overload physiology. The less frequent tracer uptake by ventricles or simultaneously by all chambers of the heart may be secondary to pressure overload or underlying valvular heart diseases ${ }^{[8]}$. Correlation with additional cardiac imaging (CT, 
echocardiography, MRI) may be useful to distinguish benign cardiac uptake from metastatic tumor and mediastinal lymphadenopathy ${ }^{[9]}$ (see Figure 3).

Lipomatous hypertrophy of the interatrial septum (LHIS) is a benign fat accumulation in the interatrial septum with a prevalence of $2 \%-3 \%$. CT at the level of the fossa ovalis shows a "dumbbell" shape due to sparing of the fossa in $78 \%$ of patients with LHIS. LHIS demonstrates a greater mean standardized uptake value (SUV) on PET/CT when compared to chest wall fat ${ }^{[10]}$. This is due to the increased amount of brown fat in LHIS, making it more metabolically active and thus FDG-avid. These features will help differentiate LHIS from malignant cardiac processes. Fat accumulation in the interatrial septum increases with patient's age and obesity ${ }^{[11]}$. The thicker and bulkier the fat infiltration of the interatrial septum, the more prominent F-18 FDG uptake is seen. The diagnosis of LHIS rests on the fat attenuation characteristics demonstrated by the transmission CT (see Figure 4).

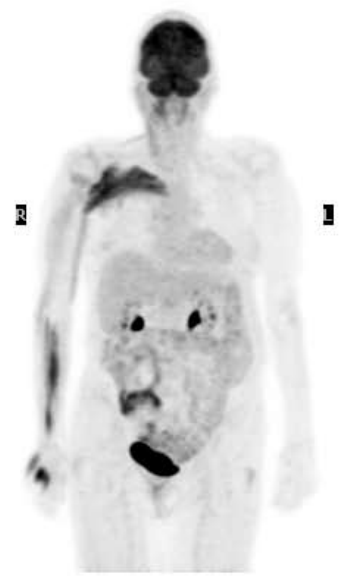

Figure 1. Whole body maximum intensity projection (MIP) image shows increased radiotracer uptake at the musculature of the right neck, right shoulder girdle predominantly at the pectoralis major and subscapularis muscles, and entire right upper extremity due to involuntary dyskinetic muscular exertion from recent seizure occurring less than 48 hours before the PET/CT imaging.

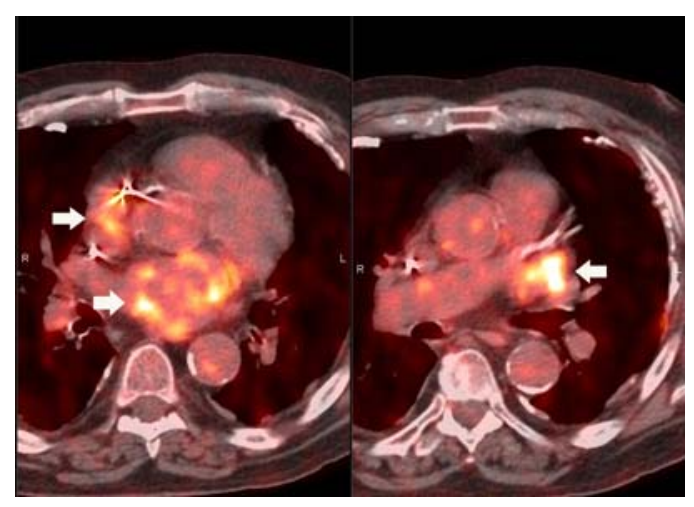

Figure 3. Composite PET/CT images show tracer uptake at the right atrium/atrial appendage and left atrium (arrows, left image) and left atrial appendage (arrow, right image), which could mimic hypermetabolic mediastinal nodal disease.
Figure 2. Whole body PET MIP image shows the classic bilateral and symmetrical pattern of hypermetabolic brown adipose tissue at the sub-occipital, cervical, supraclavicular (arrows), axillary, and paraspinal regions.

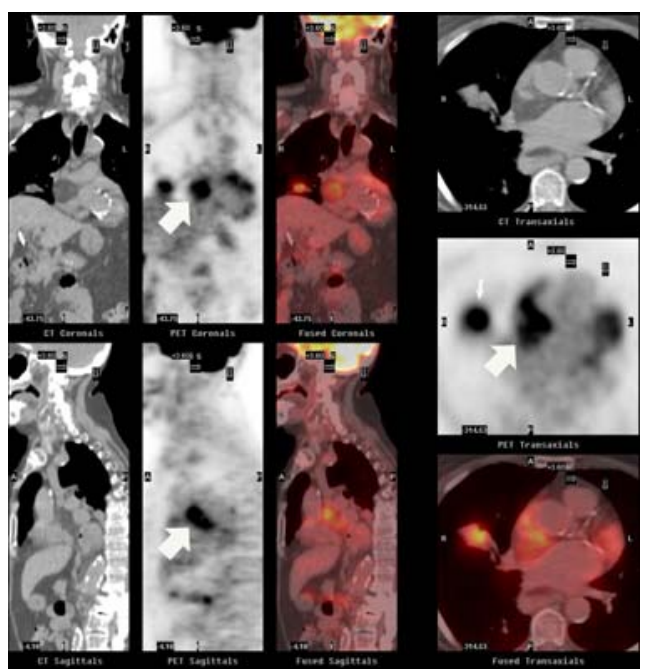

Figure 4. Composite PET/CT images show hypermetabolic lipomatous hypertrophy of the inter-atrial septum with corresponding tissue with adipose attenuation characteristics on transmission CT (arrows). A right peri-hilar hypermetabolic lung malignancy is seen on axial images (small arrow). 


\subsection{I nflammation}

Lung inflammatory pseudotumor, also known as inflammatory myofibroblastic tumor, represents a spectrum of myofibroblastic proliferations containing a varying infiltrate of chronic inflammatory cells ${ }^{[12]}$. Radiographically, it is nonspecific featuring round/oval lung nodule or mass with possible spiculations and variable degrees of contrast enhancement. Due to infiltrating inflammatory cell composition, it exhibits FDG uptake simulating malignancy (see Figure 5). Resection of the lesion is the treatment of choice. However, nonsurgical treatments such as radiotherapy and steroids have been employed in the setting of incomplete surgical resection, tumor recurrence, and patients being unfit for surgery. PET/ CT can play a role in monitoring post-radiation changes attempting to decrease surgical and further radiation treatments ${ }^{[13]}$. The definitive identification of lung inflammatory pseudotumor is histological.

Systemic IgG4-related sclerosing disease is characterized by lesions with lymphoplasmacytic infiltrative fibrosis. Also known as autoimmune pancreatitis (AIP) due to the originally reported involvement of the pancreas, this disorder also features lesions of different organ systems of the body such as the orbits, salivary glands, thyroid, gallbladder, biliary ducts, retroperitoneum, aorta, kidneys, prostate, lymphatic system, airways and lungs (see Figure 6). Lung involvement is related to IgG4-positive plasma cell and lymphocyte infiltrating the parenchyma with immunohistochemically evident fibrous interstitial proliferation in the background. Correct diagnosis of this condition is crucial because steroid therapy can be curative. Unfortunately, malignancy cannot be differentiated from the imaging findings, and tissue sampling is necessary to confirm the diagnosis of IgG4-related lung disease ${ }^{[14]}$. Within the mediastinum it can present with nonspecific bronchial wall thickening (see Figure 7). Recognizing additional areas of involvement, especially the bilateral and symmetrical orbital and salivary gland FDG-avid features, is helpful in differentiating the correct diagnosis from malignancy.

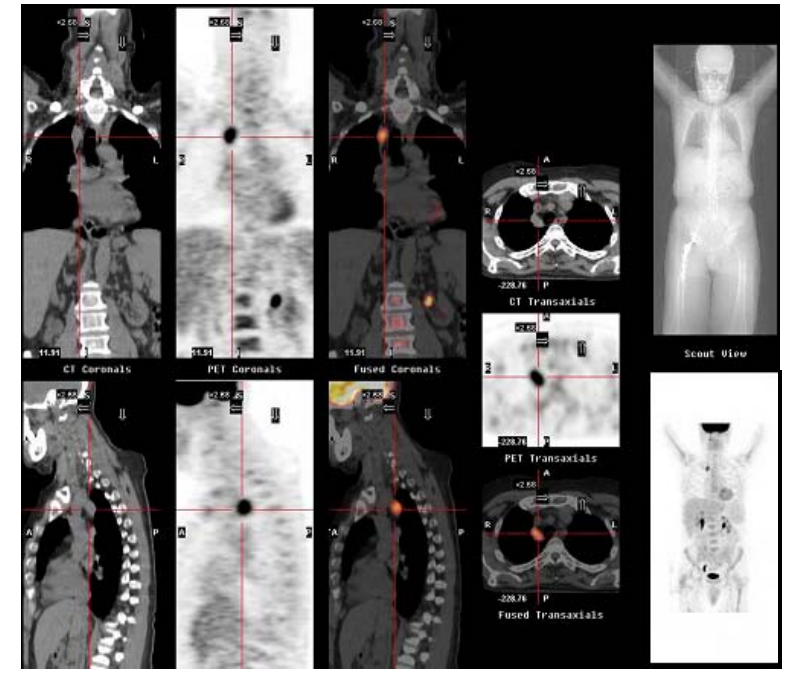

Figure 5. Composite PET/CT images show a spiculated right upper pulmonary lobe lesion with prominent trace uptake (cross-hair) suspicious for lung malignancy. Histology of the resected lesion shows an inflammatory pseudo-tumor.

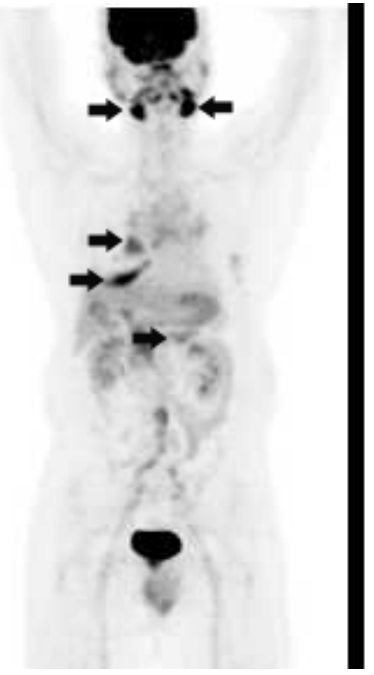

Figure 6. Whole body MIP images of a patient with IgG4-related sclerosing disease before and after corticotherapy show resolution of traced uptake at the bilateral salivary glands (top arrows), right hilar node , right lower pulmonary lobe (midlevel arrows) and pancreas (bottom arrow).

Sarcoidosis is a chronic systemic inflammatory disease of unknown origin involving preferentially lungs often with associated hilar and mediastinal adenopathy. Characteristic radiologic and PET features of thoracic sarcoidosis are well recognized by clinicians and imagers and are actually used to follow the status of patients undergoing treatment ${ }^{[15,16]}$. Since the PET features are frequently indistinguishable from other advanced neoplasms with mediastinal lymphadenopathy, histologic proof is typically necessary for the correct diagnosis of systemic inflammatory disease (see Figure 8). 
Nodal reactive process. The false positive PET findings from reactive process to foreign material mimic nodal metastasis from lung malignancy. Mediastinal node staging with FDG-PET/CT in coal workers has been rendered insufficient due to the high false-positive rates given the presence of pneumoconiosis with positive predicted values as low as $66 \%{ }^{[17,18]}$. Therefore more invasive methods of nodal sampling are necessary in differentiating anthracosis from malignancy in patients with PET positive lymph nodes and known pneumoconiosis exposure (see Figure 9).

Thyroid uptake in PET imaging poses a common conundrum amongst imagers. Diffuse uptake is typically associated with a benign pathology such as thyroiditis and focal nodular uptake may be related to hyperfunctioning nodules or malignancy ${ }^{[19]}$. Occasionally a substernal thyroid is present and can present as a focal hypermetabolic mediastinal mass on PET (see Figure 10). Three-dimensional PET/CT evaluation of the thoracic inlet is helpful to ascertain the origin of this potential lesion.

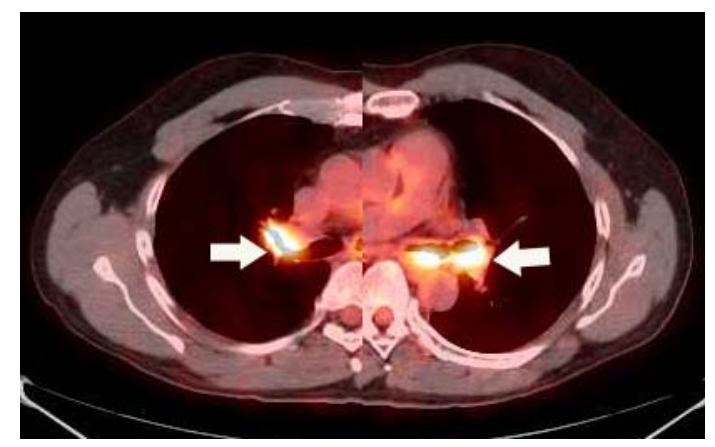

Figure 7. Composite PET/CT images show IgG4-related sclerosing lesions of bilateral bronchi with narrowing of the airways (arrows)

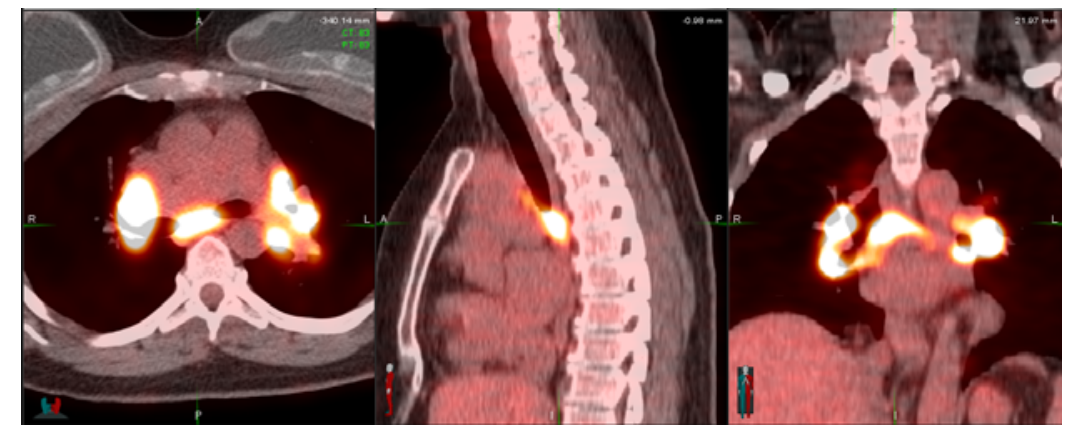

Figure 8. Composite PET/CT images show clustered hypermetabolic nodal disease in the mediastinum and bilateral hilar regions from sarcoidosis (arrows)
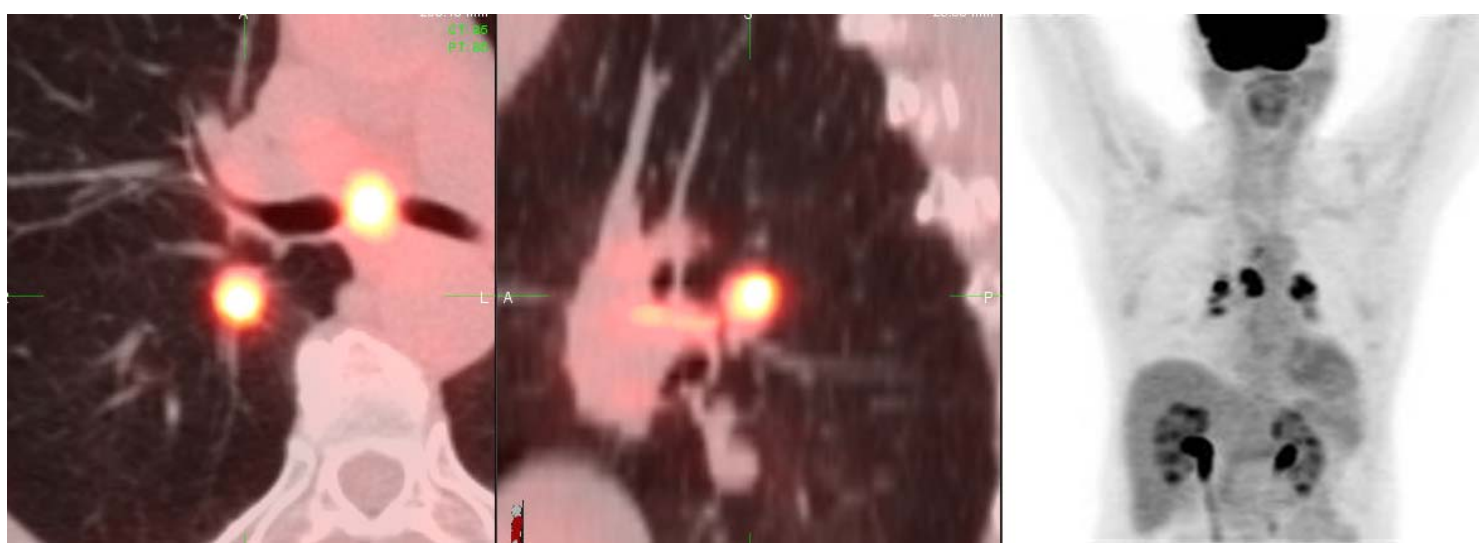

Figure 9. Composite PET/CT images in axial and coronal projections (left) and MIP image (right) show hypermetabolic adenopathy in the subcarinal and bilateral hilar regions from histologically proven anthracosis (arrows) 


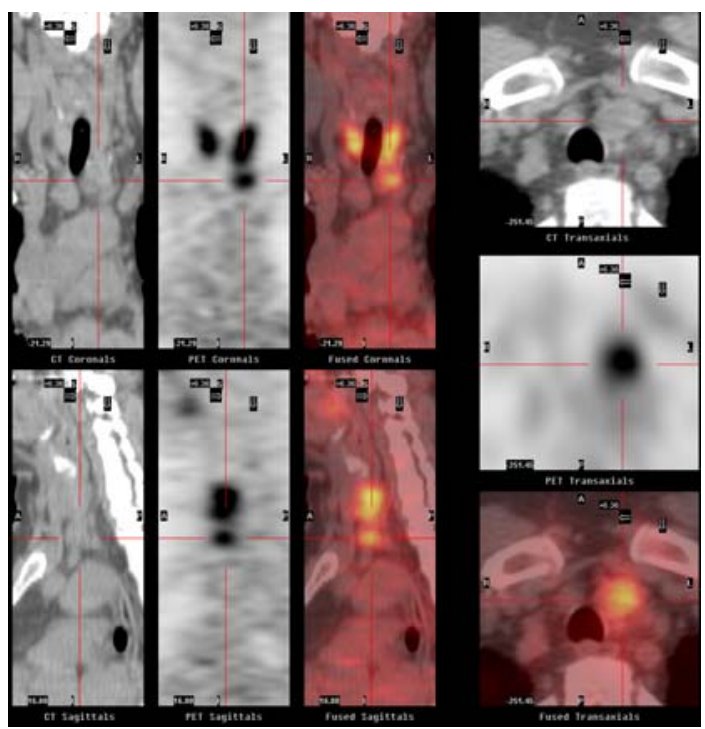

Figure 10. Composite PET/CT images show uptake features of thyroiditis with substernal component (crosshair). The diffuse pattern of F-18 FDG distribution in the thyroid gland is in favor of benign or inflammatory processes.

\subsection{Infection}

Thoracic infectious diseases may target the lung parenchyma, mediastinum or chest wall. The high concentration of macrophages and inflammatory cells and consequently high FDG avidity at sites of infection and abscess formation may mimic cancer especially at prior sites of resected/treated malignancy and the existence of cavitation reminiscent of malignant central necrosis (see Figure 11) ${ }^{[9,20]}$.

Coccidioidomycosis is an endemic fungal disease of the arid and semi-arid regions of the North, Central and South American continent and is secondary to inhalation of the arthroconidia form of Coccidioides immitis. This disease, primarily a regional public health concern, may be encountered worldwide due to the large population migration, and seasonal and recreational transit through the endemic areas. Risk factors are pregnancy, extreme stages of life, diabetes, corticosteroid use, immunocompromised health conditions and dark-skinned ethnics. Although the pulmonary manifestations of this infection vary and resemble those seen in mycobacterial infections ${ }^{[21]}$, the acute phase of the disease may present with nonspecific infectious findings such as infiltrates, consolidation, adenopathy and pleural effusion ${ }^{[22]}$ giving the appearance of a primary lung malignancy (see Figure 12).

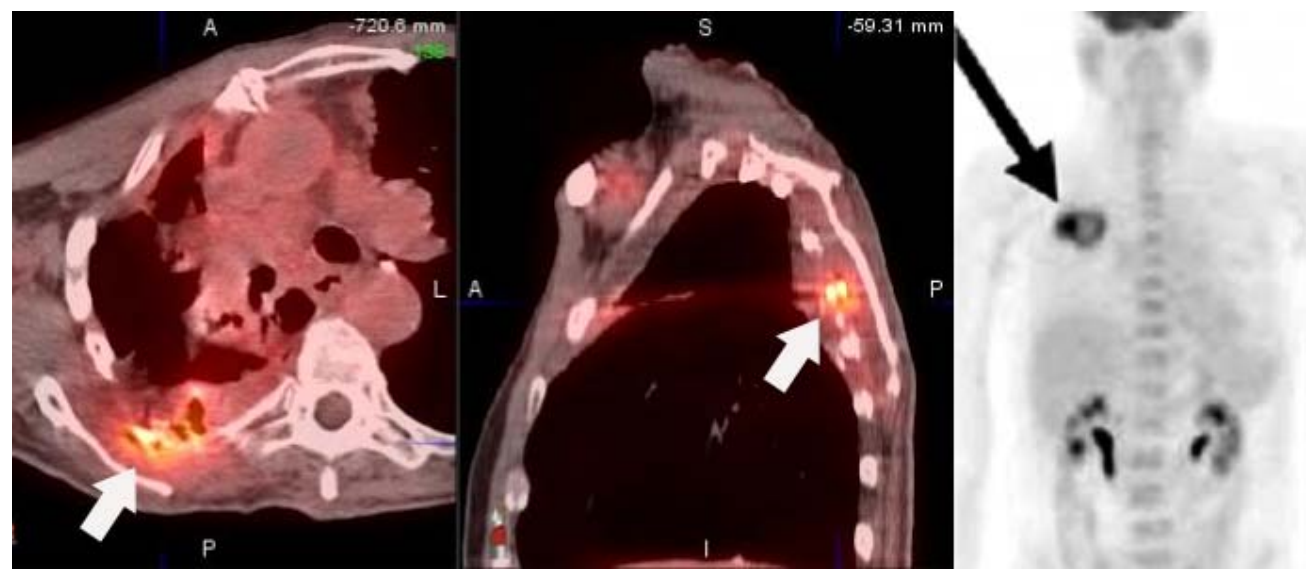

Figure 11. Composite PET/CT images (left) and MIP image (right) of the right chest wall abscess and of right upper pulmonary lobe abscess with cavitation (right) in two different patients mimicking malignancy 

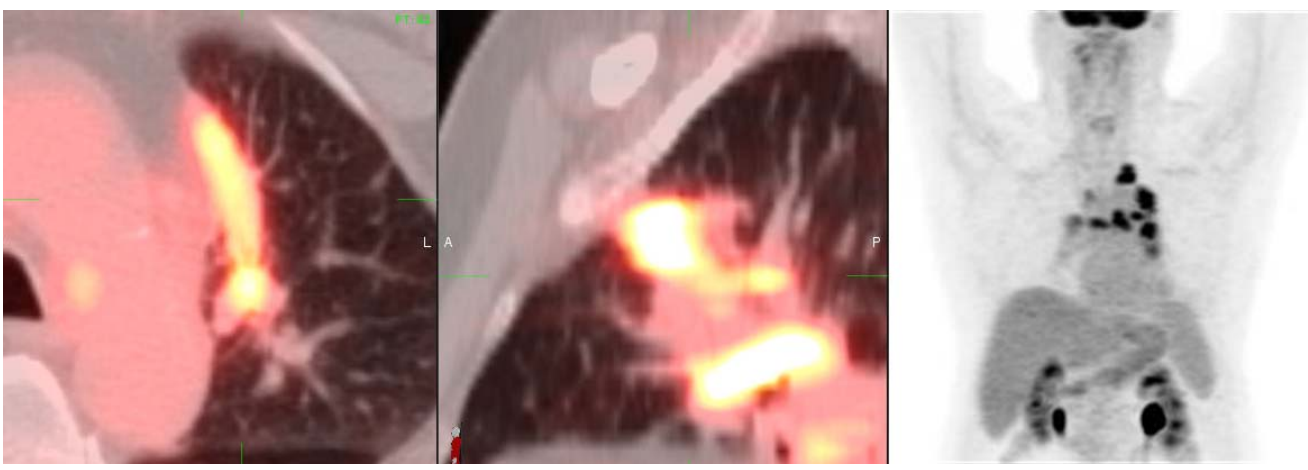

Figure 12. Composite PET/CT and MIP images show coccidiodomycosis of the medial left lung and of mediastinal and hilar nodes (arrows)

\subsection{Trauma, iatrogenic and post-procedural changes}

Post-radiation changes usually present with geographic/straight-margin features involving organs and anatomic structures subjected to this procedure such as lungs and heart. Pulmonary parenchyma involvement exhibits features of consolidation with fibrotic retraction with associated FDG uptake ${ }^{[5]}$. Patient's history and recognition of a radiation portal pattern are essential to avoid misdiagnosis (see Figure 13). Tracer uptake at the cardiac apex is related to the oblique/tangential radiation portals used for treatment of left breast cancer. Radiation-induced cardiac toxicity using myocardial imaging has demonstrated perfusion defects up to $70 \%$ of patients from 1 to 18 years post-RT for left-sided breast cancer. Radiation therapy may cause perfusion defects, wall motion abnormalities, and subtle changes in cardiac ejection fraction from 0.5 to 2 years post-radiotherapy. These perfusion defects may persist from 3 to 6 years post-radiotherapy. Furthermore, new perfusion defects may appear 3 to 6 years post-treatment in patients who had initially normal cardiac SPECT scans after treatment ${ }^{[23,24]}$. It has been suggested that a radiation dose greater than $35 \mathrm{~Gy}$ is required to result in increased FDG activity ${ }^{[7]}$ (see Figure 14).

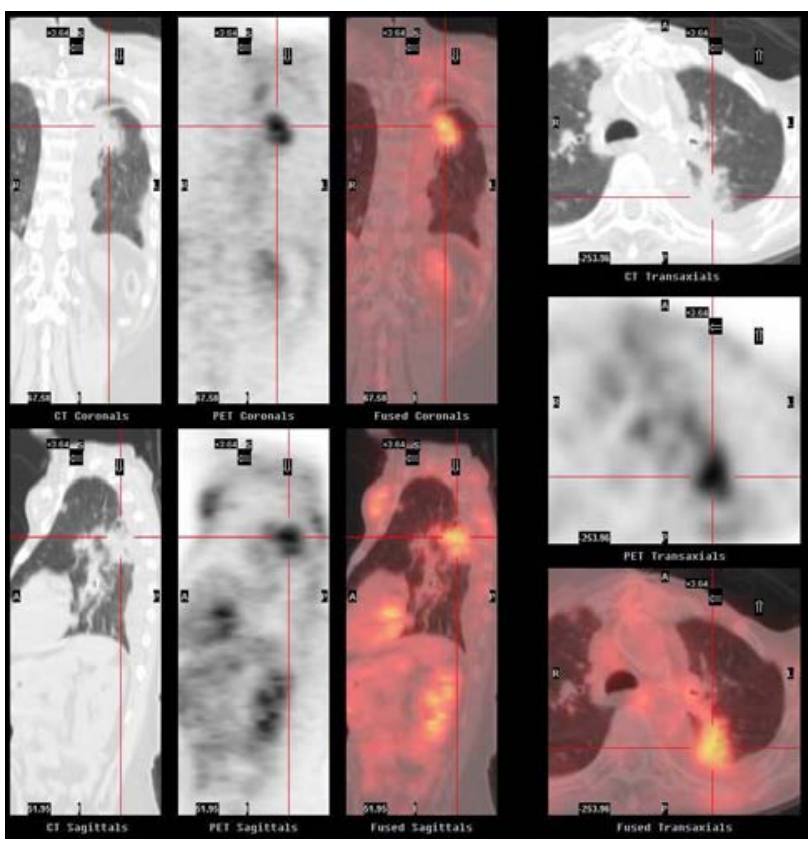

Figure 13. Composite PET/CT images show tracer uptake at the medial aspect of the left lung from post-radiation changes (crosshair)

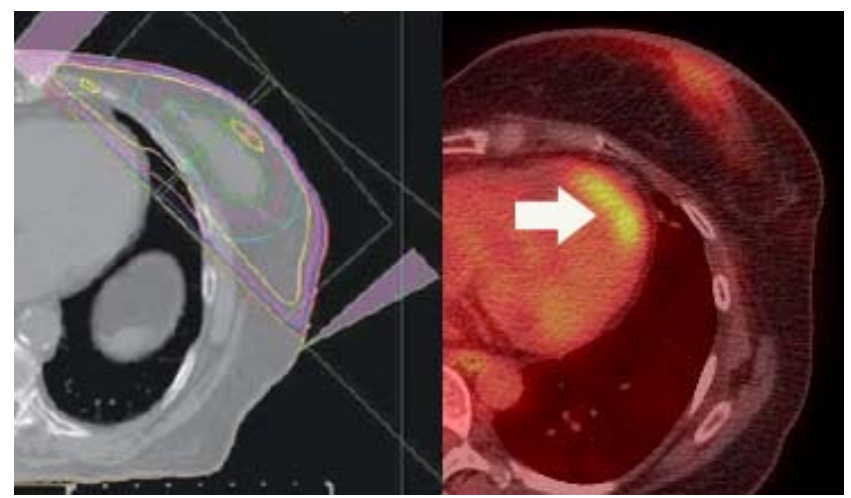

Figure 14. Composite image of the oblique radiation portal of the left breast cancer grazing the left ventricular apex (left) with resulting corresponding tracer uptake from radiation myocarditis (right, arrow) 
Talc pleurodesis is a procedure to treat persistent pneumothorax or recurrent pleural effusion. The pleural deposits stimulate a chronic granulomatous reaction that may be FDG-avid and thus mimic tumor recurrence on PET in patients treated for pulmonary or pleural malignancy (see Figure 15). The characteristic high CT attenuation of talc density from matched FDG-avid curvi-linear features helps to differentiate this entity from pleural tumors ${ }^{[1,25]}$.

Hypermetabolic lung clot as focal tracer accumulation without corresponding CT abnormality has been associated with emboli, an inflammatory reaction of a pre-existing vascular thrombus and iatrogenic injection ${ }^{[26]}$. Occasionally a complicated tracer injection can induce an F-18 FDG-labeled platelet aggregated clot to embolize causing a focus of tracer accumulation in a vascular branch without corresponding CT findings of visible thrombus (see Figure 16).

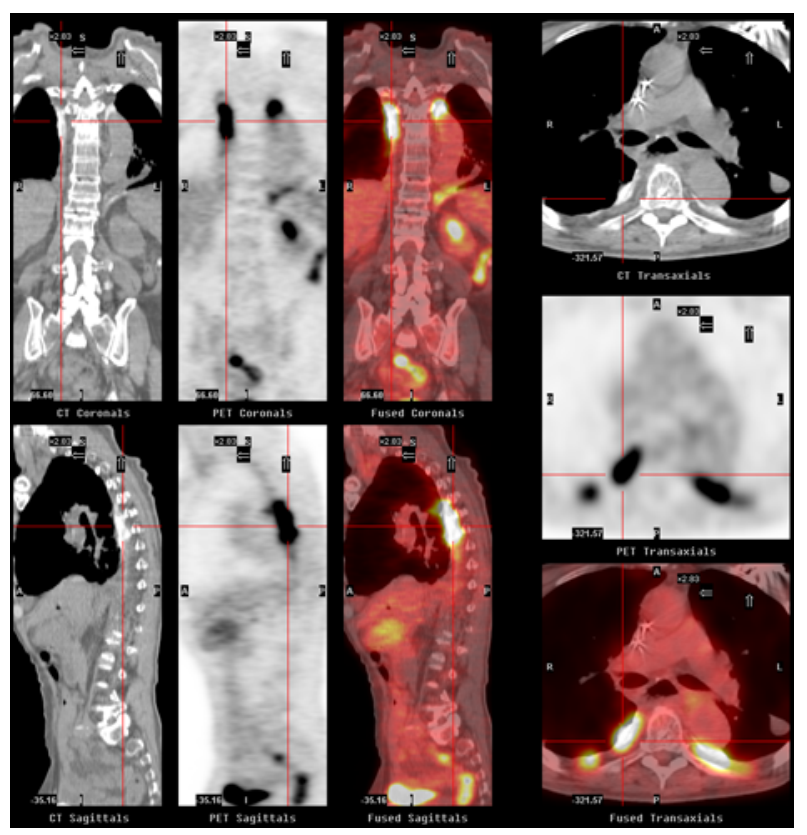

Figure 15. Composite PET/CT images show bilateral foci of curvi-linear tracer uptake corresponding to sires of calcified pleura secondary to granulomatous reaction of talc pleurodesis (crosshair).

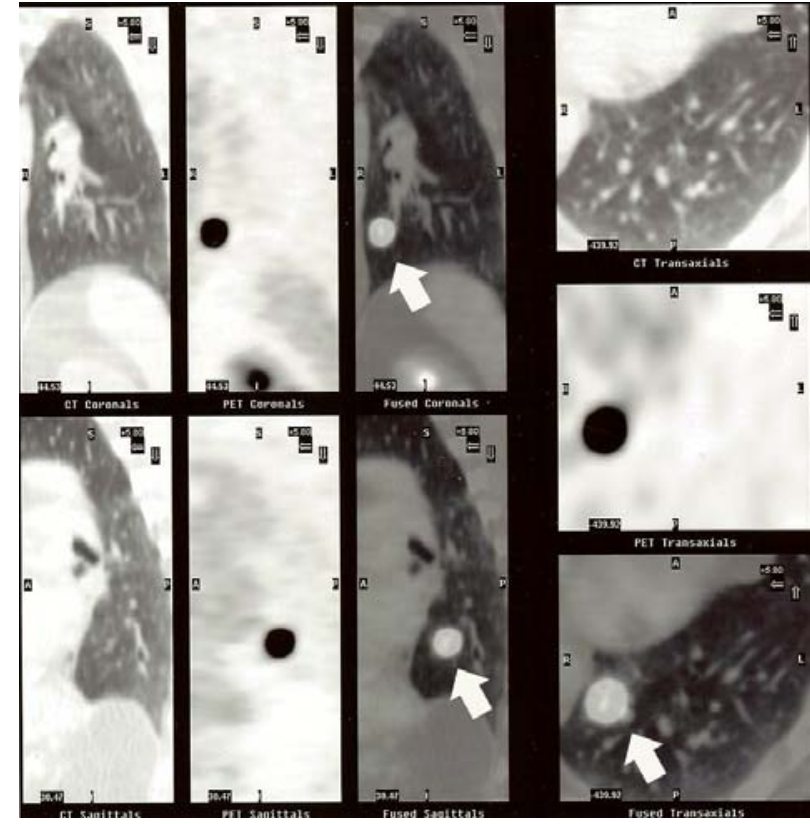

Figure 16. Composite PET/CT images show prominent nodular tracer uptake at the left lower pulmonary lobe without any corresponding soft tissue lesion on transmission CT. The finding is related to complicated upper extremity tracer injection with hypermetabolic clot (crosshair).

Mediastinal and cardiac procedures or other recent instrumentation and invasive procedures induce local and regional concentration of inflammatory cells exhibiting increased tracer uptake ${ }^{[5]}$ on PET imaging. Curvi-linear and well-defined geometric features are strongly suggestive of sequela of man-made processes such as mediastinoscopy (see Figure 17) and porcine pericardial patch repair (see Figure 18).

Osseous injury whether from trauma (fracture) and iatrogenic cause (sternotomy) can lead to increased tracer uptake on PET due to accumulation and high turnover of inflammatory cells during active osseous repair and healing processes $^{[4,5,27]}$ (see Figure 19). The difference between SUV values of benign and malignant fractures has been shown to be statistically significant and therefore can aid in interpretation of abnormal uptake in the sternum ${ }^{[28]}$. A precise surgical/ oncologic history is important when assessing the positive PET osseous findings.

Reactive bone marrow process. The FDG uptake in normal bone marrow is typically of low level. This uptake is increased diffusely with a homogenous or heterogenous manner in patients receiving chemotherapy and colony-stimulating factor medications ${ }^{[4]}$ (see Figure 20). The increased bone marrow activity may simulate malignant infiltration or interfere with the detection any underlying focal viable malignancy. Knowledge of the patient's therapeutic regimen and interval of time 
between the use colony-stimulating factors and the PET/CT imaging is important to accurate evaluation the bone marrow uptake.

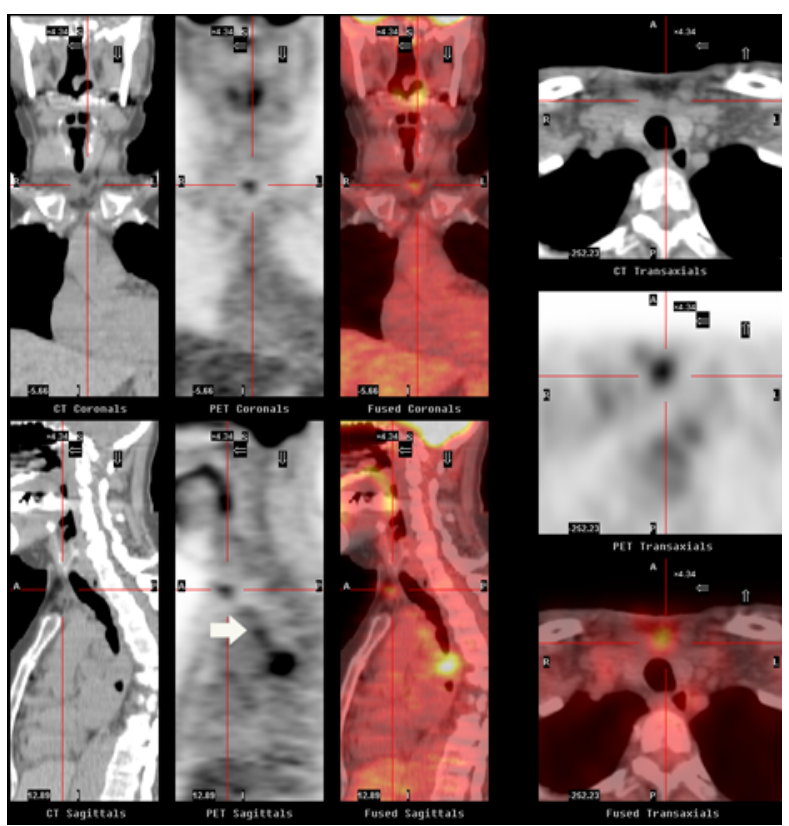

Figure 17. Composite PET/CT images show linear features of tracer uptake highlighting the tract of recent mediastinoscopy (crosshair and arrows).

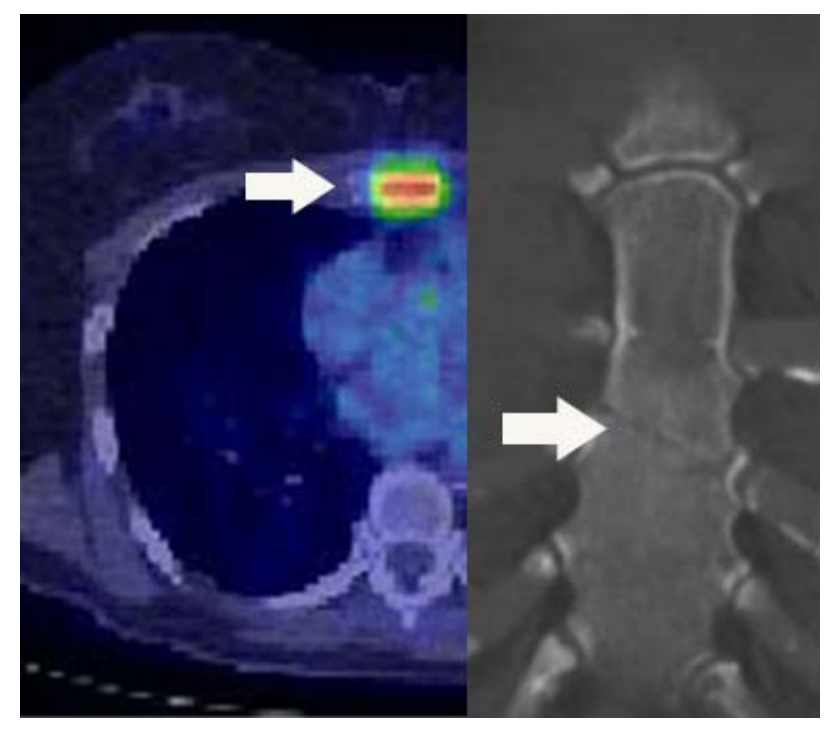

Figure 19. Composite images of axial PET/CT (left) and CT coronal reconstruction of the sternum (right) show increased tracer uptake at the site of sternal fracture (arrows).

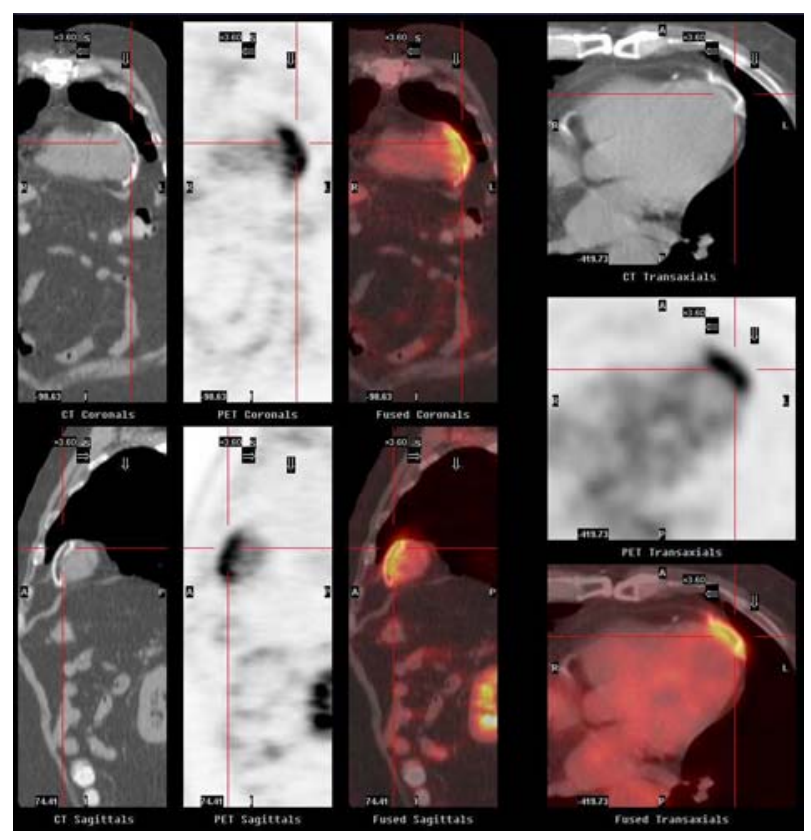

Figure 18. Composite PET/CT images shows tracer uptake of the apical cardiac patch (crosshair)

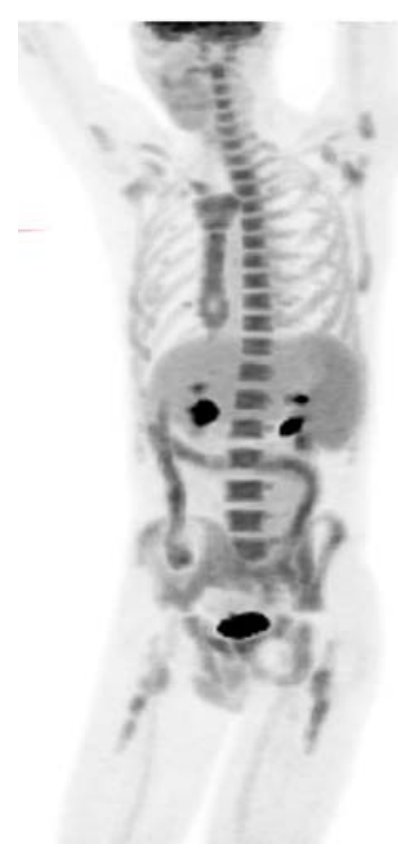

Figure 20. Whole body MIP image shows diffuse reactive marrow of the axial and appendicular skeleton secondary to chemotherapy and colony-stimulating factor medications. 


\subsection{Benign tumors}

Schwannomas involve frequently spinal nerve roots, and nerves of the head and neck, and flexor surfaces of extremities. They are usually solitary in a patient population of third to fifth decades of life ${ }^{[29]}$ with or without association with neurofibromatosis type 1 . Their prominent F-18 FDG uptake, not related to size or tumor proliferation rate characterized by the Ki-67 index may be linked to overexpression of glucose transporter proteins by the tumor cells ${ }^{[30]}$. Thoracic schwannomas may involve the mediastinum or chest wall (see Figure 21). PET/CT cannot distinguish schwannomas from malignant peripheral nerve sheath tumors or malignant nodal disease based solely on the uptake values. The diagnosis of schwannomas rests on histological identification.

Fibromatosis is a group of benign soft tissue tumors with locally aggressive behavior characterized by proliferation of fibroblasts with mature collagen ${ }^{[31]}$. It is mostly associated with Gardner's syndrome. This syndrome is a rare autosomal dominant inherited disorder characterized by intestinal polyposis, bone and soft-tissue tumors, including osteomas, epidermal inclusion cysts, lipomas, fibromas, gastric and duodenal polyposis, frequently complicated by subsequent desmoid tumors of the mesenteric and abdominal/chest wall (see Figure 22). The PET uptake features are probably related to high cellularity and mitotic activity of fibromatosis.

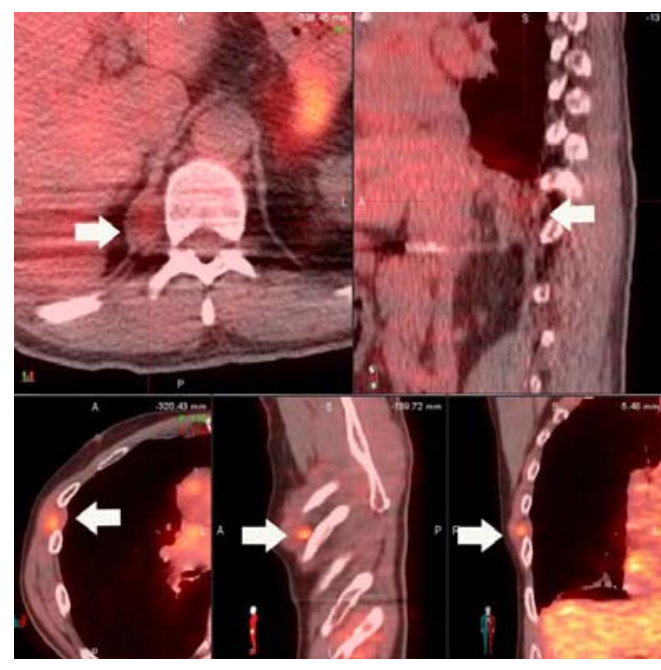

Figure 21. Composite PET/CT images show schwannoma of the infero-posterior mediastinum at right retrocrural region (top row, arrows) and of the right chest wall at intercostal location (bottom row, arrows).

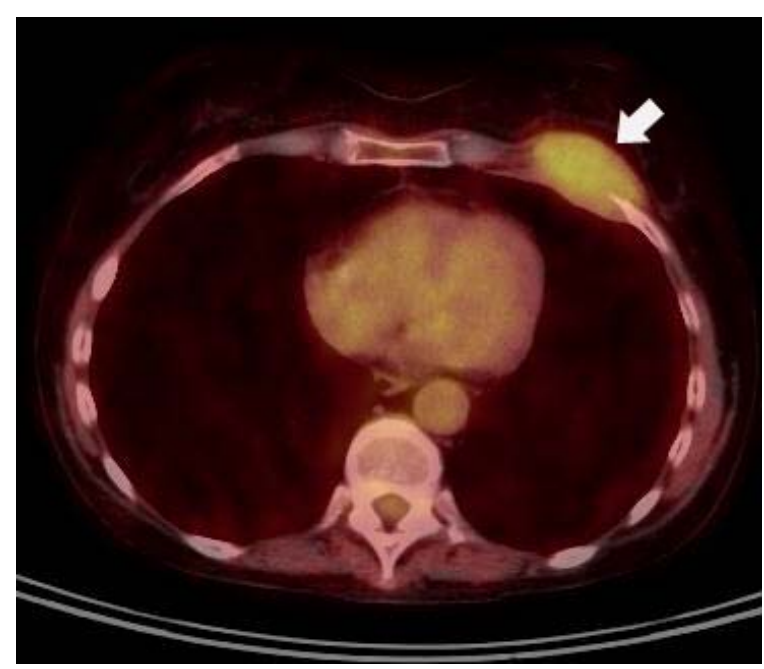

Figure 22. Axial PET/CT image of a patient with Gardner's syndrome shows a hypermetabolic left anterior chest wall desmoid encasing an adjacent rib (arrow).

Elastofibromas dorsi are benign soft tissue tumors characterized by fibroblastic proliferation and accumulation of abnormal elastic fibers with a reported prevalence on CT of $2 \%$ in the elderly population. These lesions are predominantly encountered in elderly women. They may be bilateral and asymmetrical in size in about $10 \%$ of all cases. MRI and CT show elongated soft tissue masses with combined characteristics of muscle and fat tissue. Elastofibromas are located between the ribs and serratus and latissimus dorsi musculature, deep to the inferior angle of the scapula. PET shows mild to moderate degree of F-18 FDG uptake. These cross-sectional and PET features are helpful to avoid unnecessary biopsy during evaluation of primary and secondary malignancies ${ }^{[32]}$ (see Figure 23).

Other benign bones tumors may be FDG-avid. They include osteoblastoma, chondromyxoid fibroma, aneurysmal bone cyst (see Figure 24), giant cell and brown tumor. These lesions cannot be distinguished from malignant bone tumors based on SUV and additional imaging methods (MRI, CT, and radiograph) and ultimately tissue sampling may be required for further characterization ${ }^{[33,34]}$. 


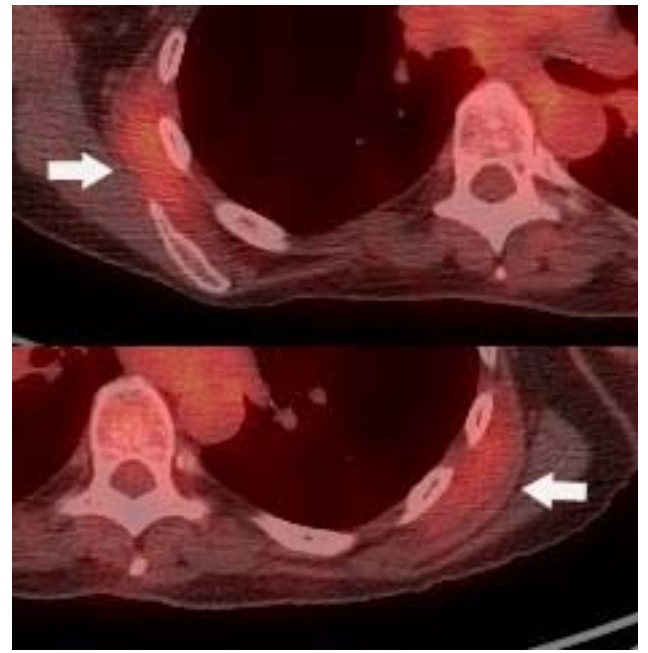

Figure 23. Composite PET/CT images of bilateral hypermetabolic elastofibroma dorsi at the postero-lateral aspect of the chest wall (right side: top image, left side: bottom image) located between the ribs and inferior aspect of the scapula (arrows).

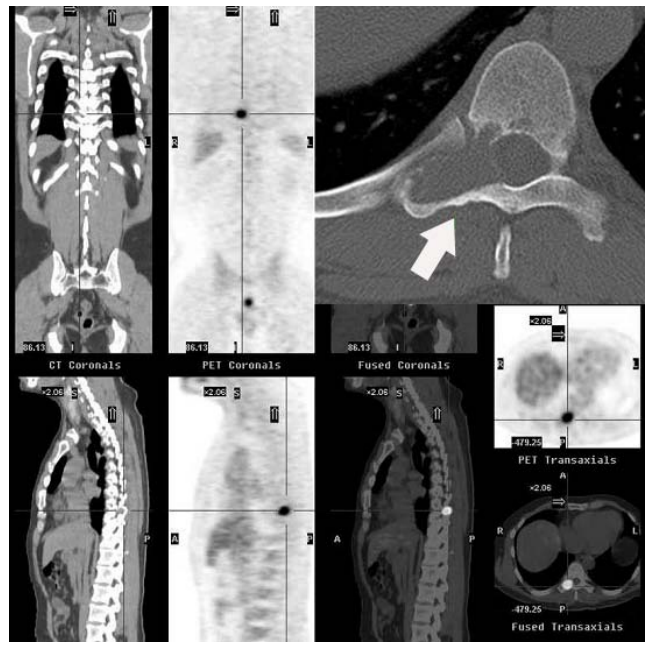

Figure 24. Composite PET/CT and CT (upper right corner, arrow) images of the aneurismal bone cyst of the right aspect of T9 with increased tracer uptake (crosshair).

\section{Conclusion}

Significant overlap regarding the appearance of inflammatory, infectious and malignant processes exists causing a potential problem in accurate PET/CT interpretation ${ }^{[35]}$. Benign processes are more inclined to exhibit bilaterally symmetrical, tubular, curvilinear, geometric, anatomic and diffuse scintigraphic features. Malignant lesions usually show a random distribution with nodular, mass-like and amorphous PET features. Correlation with clinical, radiation and surgical history remains of a mainstay of PET imaging as well as the importance of cross-check evaluation of the transmission CT of PET/CT, contemporary CT, MR and radiographs for the anatomic location and further imaging characterization of positive PET findings. For indeterminate cases, tissue sampling remains the only option to adequately identify these indeterminate lesions. The awareness of and familiarity with false-positive findings should improve the PET/CT evaluation accuracy of the thorax.

\section{References}

[1] Truong MT, Pan T, Erasmus JJ. Pitfalls in integrated CT-PET of the thorax: implications in oncologic imaging. J Thorac Imaging. 2006 May; 21(2): 111-22. PMid:16770228 http://dx.doi.org/10.1097/00005382-200605000-00003

[2] Chang JM, Lee HJ, Goo JM, et al. False positive and false negative FDG-PET scans in various thoracic diseases. Korean J Radiol. 2006 Jan-Mar; 7(1): 57-69. PMid:16549957 http://dx.doi.org/10.3348/kjr.2006.7.1.57

[3] Jackson RS, Schlarman TC, Hubble WL, et al. Prevalence and patterns of physiologic muscle uptake detected with whole-body 18F-FDG PET. J Nucl Med Technol. 2006 Mar; 34(1): 29-33. PMid:16517966

[4] Rosenbaum SJ, Lind T, Antoch G, et al. False-positive FDG PET uptake-the role of PET/CT. Eur Radiol. 2006 May; 16(5): 1054-65. PMid:16365730 http://dx.doi.org/10.1007/s00330-005-0088-y

[5] Kavanagh PV, Stevenson AW, Chen MY, et al. Nonneoplastic diseases in the chest showing increased activity on FDG PET. AJR Am J Roentgenol. 2004 Oct; 183(4): 1133-41. PMid:15385320 http://dx.doi.org/10.2214/ajr.183.4.1831133

[6] Cronin CG, Prakash P, Daniels GH, et al. Brown fat at PET/CT: correlation with patient characteristics. Radiology. 2012 Jun; 263(3): 836-42. http://dx.doi.org/10.1148/radiol.12100683 
[7] Maurer AH, Burshteyn M, Adler LP, et al. How to differentiate benign versus malignant cardiac and paracardiac 18F FDG uptake at oncologic PET/CT. Radiographics. 2011 Sep-Oct; 31(5): 1287-305. PMid:21918045 http://dx.doi.org/10.1148/rg.315115003

[8] Franceschi AM, Matthews R, Mankes S, et al. Four chamber FDG uptake in the heart: an indirect sign of pulmonary embolism. Clin Nucl Med. 2012 Jul; 37(7): 687-91 PMid:22691515 http://dx.doi.org/10.1097/RLU.0b013e31824c5e64

[9] Lobert P, Brown RK, Dvorak RA, et al. Spectrum of physiological and pathological cardiac and pericardial uptake of FDG in oncology PET-CT. Clin Radiol. 2013 Jan; 68(1): e59-71. http://dx.doi.org/10.1016/j.crad.2012.09.007.

[10] Kuester LB, Fischman AJ, Fan CM, et al. Lipomatous hypertrophy of the interatrial septum: prevalence and features on fusion 18F fluorodeoxyglucose positron emission tomography/CT. Chest. 2005 Dec; 128(6): 3888-93. PMid:16354859 http://dx.doi.org/10.1378/chest.128.6.3888

[11] Fukuchi K, Ohta H, Matsumura K, et al. Benign variations and incidental abnormalities of myocardial FDG uptake in the fasting state as encountered during routine oncology positron emission tomography studies. Br J Radiol. 2007 Jan; 80(949): 3-11. PMid:17005513 http://dx.doi.org/10.1259/bjr/92105597

[12] Kim JH, Cho JH, Park MS, et al. Pulmonary inflammatory pseudotumor--a report of 28 cases. Korean J Intern Med. 2002 Dec; 17(4): 252-8. PMid:12647641

[13] Alongi F, Bolognesi A, Gajate AM, et al. Inflammatory pseudotumor of mediastinum treated with tomotherapy and monitored with FDG-PET/CT: case report and literature review. Tumori. 2010 Mar-Apr; 96(2): 322-6. PMid:20572593

[14] Kitada M, Matuda Y, Hayashi S, et al. IgG4-related lung disease showing high standardized uptake values on FDG-PET: report of two cases. Cardiothorac Surg. 2013 Jun 25; 8: 160. PMid:23800259 http://dx.doi.org/10.1186/1749-8090-8-160

[15] Gotway MB, Storto ML, Golden JA, et al. Incidental detection of thoracic sarcoidosis on whole body F-18 fluorodeoxyglucose PET. J Thorac Imaging. 2000; 15: 201-4. PMid:10928615 http://dx.doi.org/10.1097/00005382-200007000-00010

[16] Basu S, Saboury B, Werner T, et al. Clinical utility of FDG-PET and PET/CT in non-malignant thoracic disorders. Mol Imaging Biol. 2011 Dec; 13(6): 1051-60. PMid:21161689 http://dx.doi.org/10.1007/s11307-010-0459-x

[17] M, Bensadoun ES. PET imaging in patients with coal workers pneumoconiosis and suspected malignancy. J Thorac Oncol. 2009 May; 4(5): 649-51. PMid:19395909 http://dx.doi.org/10.1097/JTO.0b013e31819d4778

[18] Saydam O, Gokce M, Kilicgun A, et al. Accuracy of positron emission tomography in mediastinal node assessment in coal workers with lung cancer. Med Oncol. 2012 Jun; 29(2): 589-94. PMid:21380783 http://dx.doi.org/10.1007/s12032-011-9879-y

[19] Nakadate M, Yoshida K, Ishii A, et al. Is 18F-FDG PET/CT Useful for Distinguishing Between Primary Thyroid Lymphoma and Chronic Thyroiditis? Clin Nucl Med. 2013 June. PMid:23816945 http://dx.doi.org/10.1097/RLU.0b013e31829b2686

[20] Bakheet SM, Saleem M, Powe J, et al. F-18 fluorodeoxyglucose chest uptake in lung inflammation and infection. Clin Nucl Med. 2000 Apr; 25(4): 273-8. PMid:10750966 http://dx.doi.org/10.1097/00003072-200004000-00007

[21] Goo JM, Im JG, Do KH, et al. Pulmonary tuberculoma evaluated by means of FDG PET: findings in 10 cases. Radiology. 2000; 216: 117-121. PMid:10887236 http://dx.doi.org/10.1148/radiology.216.1.r00j119117

[22] Kapucu LO, Metzler CC, Townsend DW, et al. Fluorine-18-fluorodeoxyglucose uptake in pneumonia. J Nucl Med. 1998; 39: 1267-1269. PMid:9669408

[23] Aznar MC, Korreman SS, Pedersen AN, et al. Evaluation of dose to cardiac structures during breast irradiation. Br J Radiol. 2011 Aug; 84(1004): 743-615. http://dx.doi.org/10.1259/bjr/12497075

[24] Prosnitz RG, Hubbs JL, Evans ES, et al. Prospective assessment of radiotherapy-associated cardiac toxicity in breast cancer patients: analysis of data 3 to 6 years after treatment. Cancer. 2007 Oct 15; 110(8): 1840-50. PMid:17763369 http://dx.doi.org/10.1002/cncr.22965

[25] Asad S, Aquino SL, Piyavisetpat N, et al. False-positive FDG positron emission tomography uptake in nonmalignant chest abnormalities. AJR Am J Roentgenol. 2004 Apr; 182(4): 983-9. PMid:15039176 http://dx.doi.org/10.2214/ajr.182.4.1820983

[26] Schreiter N, Nogami M, Buchert R, et al. Pulmonary FDG uptake without a CT counterpart - a pitfall in interpreting PET/CT images. Acta Radiol. 2011 Jun 1; 52(5): 513-5. http://dx.doi.org/10.1258/ar.2011.100448

[27] Culverwell AD, Scarsbrook AF, Chowdhury FU. False-positive uptake on 2-[1 ${ }^{8}$ F]-fluoro-2-deoxy-D-glucose (FDG) positron-emission tomography/computed tomography (PET/CT) in oncological imaging. Clin Radiol. 2011 Apr; 66(4): 366-82. PMid:21356398 http://dx.doi.org/10.1016/j.crad.2010.12.004

[28] Bredella MA, Essary B, Torriani M, Ouellette HA, Palmer WE. Use of FDG-PET in differentiating benign from malignant compression fractures. Skeletal Radiol. 2008 May; 37(5): 405-13. http://dx.doi.org/10.1007/s00256-008-0452-5

[29] Beaulieu S, Rubin B, Djang D, et al. Positron emission tomography of schwannomas: emphasizing its potential in preoperative planning. AJR Am J Roentgenol. 2004 Apr; 182(4): 971-4. PMid:15039173 http://dx.doi.org/10.2214/ajr.182.4.1820971

[30] Hamada K, Ueda T, Higuchi I, et al. Peripheral nerve schwannoma: two cases exhibiting increased FDG uptake in early and delayed PET imaging. Skeletal Radiol. 2005 Jan; 34(1): 52-7. Epub 2004 Oct 9. PMid:15480645 http://dx.doi.org/10.1007/s00256-004-0845-z 
[31] Basu S, Nair N, Banavali S. Uptake characteristics of fluorodeoxyglucose (FDG) in deep fibromatosis and abdominal desmoids: potential clinical role of FDG-PET in the management. Br J Radiol. 2007 Sep; 80(957): 750-6. PMid:17709361 http://dx.doi.org/10.1259/bjr/53719785

[32] Ochsner JE, Sewall SA, Brooks GN, et al. Best Cases from the AFIP - Elastofibroma Dorsi. Radiographics. 2006 November; 26: 1873-1876. PMid:17102057 http://dx.doi.org/10.1148/rg.266055184

[33] Aoki J, Watanabe H, Shinozaki T. FDG PET of Primary Benign and Malignant Bone Tumors: Standardized Uptake Value in 52 Lesions. Radiology. 2001 June; 219: 774-7.

[34] Costelloe CM, Murphy WA Jr, Chasen BA. Musculoskeletal pitfalls in 18F-FDG PET/CT: pictorial review. AJR Am J Roentgenol. 2009 Sep; 193(3 Suppl): WS1-WS13. PMid:19696250

[35] Alavi A, Gupta N, Alberini JL, et al. Positron emission tomography imaging in nonmalignant thoracic disorders. Semin Nucl Med. 2002 Oct; 32(4): 293-321. PMid:12524653 http://dx.doi.org/10.1053/snuc.2002.127291 